\title{
Religious Minority Identity in the Work of the Advisory Committee of the Framework Convention for the Protection of National Minorities: A Multifaceted Challenge in Evolution
}

\author{
Kyriaki Topidi
}

\section{check for} updates

Citation: Topidi, Kyriaki. 2021. Religious Minority Identity in the Work of the Advisory Committee of the Framework Convention for the Protection of National Minorities: A Multifaceted Challenge in Evolution. Religions 12: 858. https://doi.org/ $10.3390 /$ rel12100858

Academic Editors: Silvio Ferrari, Roberta Medda-Windischer and Kerstin Wonisch

Received: 3 August 2021

Accepted: 31 August 2021

Published: 12 October 2021

Publisher's Note: MDPI stays neutral with regard to jurisdictional claims in published maps and institutional affiliations.

Copyright: (C) 2021 by the author. Licensee MDPI, Basel, Switzerland. This article is an open access article distributed under the terms and conditions of the Creative Commons Attribution (CC BY) license (https:/ / creativecommons.org/licenses/by/ $4.0 /)$.
European Centre for Minority Issues, 24937 Flensburg, Germany; topidi@ecmi.de

\begin{abstract}
The Framework Convention for the Protection of National Minorities (FCNM) of the Council of Europe counts more than 20 years of existence in the European human rights landscape. Normatively, the protection of minority religious identity is embedded in three main articles of the convention: first, under Articles 7 and 8, which outline a general right to freedom of religion, but also under Article 6, which considers religious minority rights for "new" minorities as related to tolerance. The analysis that follows here will unfold in three stages: the first stage will engage with the crucial issue of the scope of protection of the FCNM and how this relates to the protection of religious minority rights contained in the convention in today's European societies. The second stage will focus on the main relevant articles of the FCNM that concern religious freedom. Starting with Articles 7 and 8 of the FCNM that focus on the religious rights of minorities stricto sensu, the discussion will then extend to Articles 5 and 6 of the FCNM due to their relevance to the exercise of religious rights by minorities in their cultural and diversity management dimensions. This extension is necessary to illustrate the current implications of religious identity for minority-majority relations. Methodologically, the study relies heavily on a detailed survey of the four completed cycles of monitoring, mapping the typology of issues pertaining to religious minorities as encountered by the Advisory Committee to the FCNM (ACFC) in the monitored states. The final stage of the analysis will provide some concluding thoughts on the general contribution of the ACFC towards standard setting on religious freedom in the European context.
\end{abstract}

Keywords: FCNM; ACFC; Europe; national minorities; human rights; minority rights; religion; diversity

\section{Introduction}

The Framework Convention for the Protection of National Minorities (FCNM) of the Council of Europe counts more than 20 years of existence in the European human rights landscape. The opinions of the Advisory Committee on the Framework Convention (ACFC) constitute the backbone of a regular monitoring process that began its fifth cycle in 2018. ${ }^{1}$ These opinions form the basis for state-by-state resolutions for the Committee of Ministers of the Council of Europe. The well-known procedural dynamic in the workings of the FCNM monitoring relies on the Committee of Ministers Recommendations (as per Articles 24-26 of the FCNM) on the basis of the opinions delivered by Advisory Committee members, which are composed of independent experts. More substantially, however, ACFC opinions represent an attempt to incite legislative and policy change for the better of minority affairs among the signatory states. ${ }^{2}$

The specificity of the FCNM mechanism lies in the fact that no jurisdictional means of enforcement are foreseen. This shifts considerable practical weight (and expectations) on the ACFC to propose theoretical and practical means in a non-adversarial fashion for states to handle questions concerning aspects of minority identity (Hofmann et al. 2018, p. xi). The approach of the AC's to the monitoring of the FCNM is thus not based on legally 
binding pronouncements but rather on "soft law" tools, guided by political dialogue and persuasion. The slow pace of improvements and progress has, however, brought about a certain sense of "monitoring fatigue", not only on states who may choose to resist change, but also on stakeholders and minority groups who had hoped for change (Hofmann et al. 2018, pp. 14-15).

Initially conceived as a legal instrument that calls for a dynamic and evolving interpretation, the FCNM has been often called upon to adjust to newer developments in and challenges for minority protection in Europe. ${ }^{3}$ It is precisely this dimension that has made it a relevant body of normative statements for aspects of religious minority identity in Europe. This is also particularly so due to the fact that the conceptualization and positionality of religious minorities within the wider spectrum of the legal minority protection framework in Europe is multidimensional, touching on religious, spiritual, ethnic, or even social identity.

While the tension between non-discrimination, as the preferred means of minority protection, and a more pro-active and substantive interpretation of equality that would allow minorities to resist assimilation is not entirely eased in minority legal studies, nondiscrimination is currently openly deemed insufficient to remedy patterns of exclusion of certain groups. Minorities continue, nevertheless, to be conventionally treated as objects of "integration" by states. At the same time, there is considerable critique addressed to the concept of integration. "Inclusion" is increasingly put forward as a less contested term to describe a society in which differences based among several criteria, including religion, are not obstacles to social interactions.

The work of the ACFC has been additionally marked by a related and well-known conceptual struggle with major implications for religious minority identity: the dichotomy between "old" and "new" minorities. Echoing the Human Rights' Committee position, according to which "just as they need not be nationals or citizens [members of minorities] need not be permanent residents", the ACFC has consistently argued for the extension of the scope of application of the FCNM in order to prevent arbitrary and unjustified distinctions between specific groups of persons by states parties. ${ }^{4}$

Within this frame, the role of the AC remains essentially investigative, and aims to examine the features surrounding the implementation of the provision of the FCNM by states parties. Its sources are varied, and range from the reports of states themselves, to NGOs, experts, and other IGOs, all the way to minority organizations as stakeholders (Phillips 2002 , p. 6). The expectation from this type of monitoring is to map the general trends with regard to the protection of the religious rights of minority groups as recognized within the Framework Convention, including outside an individual claim-based framework.

Normatively, the protection of minority religious identity is embedded in three main articles of the convention: first, under Articles 7 and 8, which outline a general right to freedom of religion, but also under Article 6, which considers religious minority rights for "new" minorities as related to tolerance. Occasionally, limited references to religious minority issues can be found also in other Articles, such as Article 5 of the FCNM, or, more recently, Article 9 of the FCNM. In the early monitoring cycles, the general religious rights provisions of the FCNM received limited attention in the monitoring activities of the AC (Hofmann 2004, p. 76). The second and third cycles signalled the beginning of a more detailed consideration of many aspects of the religious identity of national minorities, with overlap among articles of the convention, but also with evolution in the analytical depth of the ACFC's assessments.

The analysis that follows here will unfold in three stages: the first stage will engage with the crucial issue of the scope of protection of the FCNM and how this relates to the protection of religious minority rights contained in the convention in today's European societies. The second stage will focus on the main relevant articles of the FCNM that concern religious freedom, namely Articles 7, 8, 6, and 5, deliberately presented in this order which aims to demonstrate the broadening and the spill-over of the implications of religious identity in the web of state obligations contained within the FCNM. Starting with 
Articles 7 and 8 of the FCNM that focus on the religious rights of minorities stricto sensu, the discussion will then extend to Articles 5 and 6 of the FCNM due to their relevance for the religious rights' exercise of minorities in their cultural and diversity management dimensions. This extension is necessary to illustrate the current implications of religious identity for minority-majority relations. Methodologically, the study relies heavily on a detailed survey of the four completed cycles of monitoring, mapping the typology of issues pertaining to religious minorities as encountered by the ACFC in the monitored states. The final stage of the analysis will provide some concluding thoughts on the general contribution of the ACFC towards standard setting on religious freedom in the European context.

\section{The Scope of Protection of the FCNM and Religious Minorities: Why Religious Minority Identity Matters Even More}

The main background consideration in the evolving treatment of religious minorities in the ACFC's monitoring work revolves around the tension between integration and the maintenance of religious identity from the minority group's perspective. ${ }^{5}$ This tension is particularly evident for immigrant (or "new") minority groups. It becomes linked to the broader question of the treatment of religious minority identity within the FCNM. In light of the FCNM's goal to provide "space for diversity and for being 'different' in society", religious minority rights have gained in prominence as a group of rights due to the emergence of multiple identities of individuals, as well as their increasing mobility. A "dynamic interpretation" of the FCNM, following the example of the ECHR, ${ }^{6}$ is sought after by the ACFC, and as such cannot exclude the consideration of religion as a significant identity marker. An understanding of minority rights as entitlements with individual, social, and collective dimensions overlaps with the multiple facets of religious freedom of belief. ${ }^{7}$ A central component of the struggle is reflected in the growing linkage between Articles 3 (the scope of the convention) and 6 (tolerance and protection of minority identity) of the FCNM: in simpler and often recounted terms, the issue remains centred on the extent to which certain religious minorities can benefit from the protection of the Framework Convention, due to their relatively recent arrival in a number of European states, in light of the states' duty to promote intercultural dialogue and protect threatened members of (religious) minorities.

The risk for the segregation of minority groups into parallel and unconnected societies has become particularly relevant for religious minorities on the occasion of the recent migratory waves, but equally concerns religiously different minority groups that are territorially settled in states parties for longer periods. States consistently invoke "state identity" or "the respect of the values of the state" to resist calls for inclusion of religious minorities, especially if they are "visible" within society. The expectation is that religious minorities accept the "dominant way of life". This expectation denies, nevertheless, the possibility that both majoritarian as well as minority religious groups evolve and crossfertilize. While value conflicts are not to be excluded, following the mainstream implies that minority religious groups are denied a contribution in shaping the national culture and identity. Equally questionable is the understanding of state neutrality vis-à-vis religion(s), not as a principled regulation of the freedom of religion for all groups, but rather as the affirmation of the choices, preferences, and symbols of the religiously dominant group within a state. But is minority religious identity an isolated element in a group's status within a state, or is it rather entangled with access to other rights? Joppke noted in 2012 that "the core cause of European integration problems may in fact be socioeconomic in nature rather than religious. Poverty and exclusion above all fuel the politicization of cultural differences ( . . )." A relevant approach to religious freedom in the contemporary European space can only be, therefore, intersectional, and connected to societal realities. Such an approach speaks in favour of the FCNM's expansion in its scope of protection of religious rights to "new" minorities, although this claim is resisted by states parties. 
The requirements of citizenship and historical presence traditionally negatively influenced the scope of application of the convention to immigrant groups. The resistance of states to extend coverage to these groups is well-documented. ${ }^{8}$ Yet, the AC has attempted on several occasions to promote with states the possibility to extend the convention for their benefit as well. ${ }^{9}$ This is partly rooted in an interpretation of the rights contained in the FCNM as independent from traditional presence on a state's territory. ${ }^{10}$ The recommended shift is explicit within the ACFC's fourth Thematic Commentary entitled "The Framework Convention' A Key Tool to Manage Diversity through Minority Rights: The Scope of Application of the FCNM", at least for a number of rights contained in the convention. ${ }^{11}$ With the notion of integration being criticized as disguised assimilation in the practices of states, and its gradual replacement by inclusion, the goal of the FCNM shifts to a differentiated target that centres on diversity management of super-diverse societies beyond an individual rights-based approach.

In this respect, the approach of the ACFC can be compared and contrasted with the one chosen by the European Court of Human Rights (ECtHR), which had earlier placed in its case law the onus of integration on the migrant, as opposed to the state. ${ }^{12}$ The ECtHR's approach entailed an examination of several elements to assess the migrant's level of integration, such as acquisition of nationality, links to country of nationality, language, or labour market integration. Such an approach alleviates the state from any obligation to facilitate the migrant's integration. The concern over the transfer of duty observation from states to immigrants is reflected in other fora of international monitoring as well. ${ }^{13}$

Such an angle to the committee's monitoring approach can be better served by an article-by-article approach undertaken by states when implementing the convention, whereby religious minorities would not be by definition excluded from the totality of the rights included. In that respect, the ACFC has identified a number of rights that concern all minority groups, especially as they contribute to a more tolerant and inclusive society. According to the ACFC's interpretation of the convention rights, Articles 6(1) and 12 of the FCNM apply to all persons residing on the territory of states parties; Articles 4, $5,7,8,9,10(1), 10(3), 11(1), 11(2), 12(3), 14(1), 14(3)$, and 15 apply to persons belonging to national minorities, whether or not they are recognized by states parties; and Articles 10(2), 11(3), and 14(2) depend on any conditions set by states parties for their scope, given the financial/administrative commitment that they entail from them. ${ }^{14}$ To support that claim further, Article 6 of the FCNM refers to "all persons living on [states'] territory."15 This approach, however, has its limitations, as no specific parameters are proposed to determine whether religious minority groups qualify for state support to maintain their separate religious or other aspects of identity. However, even for rights that entail explicit financial and administrative commitments by states, the ACFC has reverted to arguments based on the need and interest of promoting open and inclusive societies to convince states to enlarge the scope of application of the convention. ${ }^{16}$

In addition, the traditional perception within international human rights monitoring mechanisms (mainly promoted by states themselves) that resists closer scrutiny of state practice due to possible implications on the prevailing national identity and values is practically challenged by the increased population movements that occur today. The same perception is also questioned by the levels of societal conflict prevailing in a good number of European states, ${ }^{17}$ in connection to aspects of these groups' social and cultural integration. Article 3 of the FCNM declares:

"Every person belonging to a national minority shall have the right freely to choose to be treated or not be treated as such at no disadvantage shall result from this choice of from the exercise of the rights which are connected to that choice ( ... )."

Consequently, the existence of a minority within a state is framed as a question of fact, rather than law. Without the possibility to exercise self-identification, the content of the article - but also the spirit of the entire convention—loses significant weight. The second 
part of Article 3 embodies the possibility and legal entitlement for groups to develop their cultural identity, including their religious faith "in community with others".

More broadly, essentially rooted in security concerns and well before the birth of human rights, at least as they are presently known, religious minorities have been historically treated as a "threat" to the prevailing status quo in European societies. Curiously, however, for a considerable period, religious minorities have seen their equality and non-discrimination claims treated, for the most part, as violations of their freedom of religion/belief, and not under a minority protection frame (Ghanea 2012, p. 61). The monitoring of the ACFC has the potential to conceptualize a different dynamic through its monitoring activities. After all, the creation of minority rights has been convincingly linked with religious minorities and their protection in the European historical legal human rights landscape since their inception a few centuries ago (Ghanea 2012). An inclusive approach can become even more justified insofar as the nature of the claims of minority groups very often entails cultural elements of their faith, such as customs, symbols in dress, dietary codes, religious rituals, or a differentiated calendar. It can also be supported by the empirical dimension of the operations of the ACFC, whereby the existence (and its implications) of a minority group is treated as an objective question of fact rather than a matter of state recognition, as already mentioned.

The interwoven links between cultural survival and socio-economic and political participation are by now particularly evident for religious minorities present in the territory of states parties. Maintaining a distinct religious identity, therefore, impacts the cultural development of the groups concerned, and is connected also with the need for a balanced interaction with the majority. More often than not, the dynamic of the interaction between the majority religion and the minority religious group is filtered through the state's role, which can choose to adopt a preferential treatment/relationship with the majority faith organisation of a given state. This arrangement implies an unequal distribution of resources, ultimately penalizing religious minorities. The ACFC, as analyzed below, is in the process of producing a corpus of policy and legal guidelines that showcase the patterns of inequality as they are connected to religious difference.

\section{Overview of ACFC Monitoring on Provisions Related to Religious Minority Identity}

\subsection{Article 7 of the FCNM}

According to Article 7 of the FCNM, "[t]he Parties shall ensure respect for the right of every person belonging to a national minority to freedom of peaceful assembly, freedom of association, freedom of expression, and freedom of thought, conscience and religion". According to Thematic Commentary No. 4, this article also includes under its scope of protection members of minorities who are not recognised as such by the respective state party. ${ }^{18}$ Thus, Article 7 of the FCNM is of specific relevance to persons belonging to national minorities, but does not exclude from its coverage any other person belonging to a non-recognised national minority. ${ }^{19}$ A priori, it is additionally foreseen in Article 23 of the FCNM that rights in the Framework Convention should be interpreted in conformity to the European Convention of Human Rights (ECHR) and its corresponding provisions (Fontaine 2018, p. 168). As such, the interpretation of state duties in this article should be aligned with those included in Articles 9-11 of the ECHR. With the acknowledgement that the FCNM "is neither constrained by static definitions, nor by the question of who should be considered as a national minority or who should not" 20 , Article 7 of the FCNM is, justifiably, broadly interpreted. States parties, nevertheless, often resist this extension in the scope of application of the provision using a variety of criteria. ${ }^{21}$

Despite the fact that the freedoms guaranteed in Article 7 of the FCNM are essential towards the implementation of minority rights, the review of AC opinions on Article 7 issues in relation to aspects of religious freedom from a minority perspective shows a limited span. In its essence, Article 7 of the FCNM is a broad provision that includes several types of minority rights with a pronounced collective dimension. Concerning freedom of 
religion/belief, the AC's approach is quasi-thematic: it focuses on freedom of association through the constitution of political parties, including along religious lines, though only indirectly. ${ }^{22}$ In that context, it stresses the importance of the collective dimension of religious freedom exercised through political party formation based on religious affiliation among others, criticizing any restriction imposed by states which, by the nature of its broad character, disproportionately impacts the exercise of Article $7 .{ }^{23}$ The ACFC adds that, by allowing the formation of such parties, states would contribute more meaningfully to the peaceful coexistence of groups. ${ }^{24}$

A second recurring theme in the AC monitoring overview relates to religious education, especially in countries recognizing a dominant/preferred faith for historical or other reasons. The example of the Second Opinion in Norway ${ }^{25}$ is illustrative of this: the ACFC's approach is to encourage states to "afford all the attention needed to the other religious communities" beyond the majoritarian one. Religious education ${ }^{26}$ in state schools in objective and neutral terms is, for example, approached as including general and cultural knowledge of the various religions, without preference given to one (majoritarian) system of faith. The use of a system of exemptions from religious courses for religious minorities is at the same time identified as potentially stigmatizing for pupils that opt out. The opinion on Norway is interesting as it echoes the contemporaneous ECtHR case of Folgero $v$. Norway $^{27}$, through the use of similar arguments with those made by the Strasbourg court.

The balancing act in designing religious education content in public schools can acknowledge the position of dominance of a particular faith, though not without limitation. The AC finds "it legitimate to recognise the special contribution of particular religions to the historical heritage of a country. ( . . ) [T] his recognition must not undermine the principles of equality and freedom of conscience of persons belonging to national minorities." ${ }^{28} \mathrm{An}$ additional element, in that respect, stresses that religious education should not have a coercive character for pupils toward a specific religion or belief. ${ }^{29}$

More peripheral issues linked to Article 7 of the FCNM include the treatment of minority religious groups as targets of legislation countering and prosecuting extremism (securitization) $)^{30}$, and coercion of members of a particular religious minority to adopt traditional religious clothing. ${ }^{31}$

\subsection{Article 8 of the FCNM}

Article 8 of the FCNM calls for states parties to the FCNM "to recognize that every person belonging to a national minority has the right to manifest his or her religious or belief and to establish religious institutions, organisations and associations". ${ }^{32}$ More focused when compared to Article 7 of the FCNM, this provision requires a proactive stance from states that is conducive to creating and maintaining the necessary conditions for members of religious minorities to manifest their religion or belief. This duty covers the establishment of religious institutions and organisations, but does not go as far as a duty to finance or actively contribute to the establishment of religious institutions or organisations.

The guiding principle in assessing the level of fulfilment of the duty in question is the principle of equality and non-discrimination, as a guarantee that no disadvantage is arising from the choice to exercise or not to exercise the right to religious freedom. Hence, the connection between Articles 8 and 4 (on non-discrimination) of the FCNM can be established. The former is also linked with several other convention articles, such as Articles 5, 6, 10, 11, or even Article 9, given the increasing use of the online space (Malloy 2018, p. 177). In this sense, Article 8 of the FCNM can be interpreted as a "lens" that allows religion to be considered as an integral part of minority identity beyond culture, both in terms of belonging but also in terms of manifestation.

The typology of issues discussed under Article 8 of the FCNM has included the topics of the registration of religious organizations/associations, the restitution of religious property, religious intolerance and hatred, as well as, once more, religious education. The material scope of issues covered, particularly in the early cycles of AC monitoring of the 
FCNM, is also somehow limited. It has focused (predictably) on the aspects of the exercise of religious freedom that is related to the various facets of the manifestation of religious beliefs. Monitoring has, nevertheless, included-albeit to a lesser extent-the scrutiny of a state's duty of non-interference with the exercise of religious freedom, unless public safety concerns and interests are satisfied and, in any case, prescribed by law.

Religious pluralism as a guiding normative goal has prompted the ACFC to reflect also on the compatibility of the establishment of state religion with the protection of religious minority identity. The implication of the recognition of a particular religion as "preferred" or "traditional" 33 by states, with an understanding that the designation of a church as "established" is not contrary to the FCNM. The point of tension, however, remains the (un)equal distribution of benefits and funding by states among majority and minority religious organizations, especially when the difference of treatment between them is unjustified. ${ }^{34}$ The main criterion applied in the $A C^{\prime}$ s opinions for the distribution of public financing towards religious communities is non-discrimination. ${ }^{35}$

The ACFC has particularly emphasized the modalities of the management of religious property, such as the restitution of church property to minority religions, ${ }^{36}$ the building and/or reconstruction of religious buildings, ${ }^{37}$ or the availability of burial sites. ${ }^{38}$ Practices where states follow, in a discriminatory manner, procedures to return confiscated properties to religious groups are highlighted as dissonant to Article 8 of the FCNM. ${ }^{39}$

The registration of religious communities, as a recurring theme, is considered as an important pre-condition for the functioning religious organizations to pursue their activities, though this is not always indispensable. ${ }^{40}$ The AC has acknowledged, however, that registration is important in order for minority religious organisations to benefit from a number of rights, such as the right to acquire legal personality or to construct religious buildings, ${ }^{41}$ but also to guarantee legal certainty for religious organizations, in particular against lengthy and unpredictable proceedings. ${ }^{42}$

The arbitrary application of national legal frameworks is also highlighted when authorities reject applications of minority religious organizations to register for obscure procedural reasons, or when they attempt to "securitize" the exercise of religious freedoms. ${ }^{43}$ The latter point is particularly relevant for a number of Muslim communities. ${ }^{44}$

Another pattern observed, in terms of registration, is the requirement from states to allow only one community to register for each denomination. ${ }^{45}$ This practice usually protects the "established" churches in a given state, and is contrary to Article 9(2) of the ECHR as it imposes a restriction to the freedom to exercise one's religion or belief. All of the above has a clear impact on the religious communities' right to self-identification as stipulated in Article 3 of the FCNM, ${ }^{46}$ establishing, by extension, a closer link between the two articles of the convention. The AC makes a regular point to connect its opinions on the modalities of the registration of religious communities with Article 9 of the ECHR and the ECtHR's case-law. ${ }^{47}$

In sum, the implications for the collective exercise of religious freedom are particularly evident in the case of Article 8 of the FCNM. Religious education in public schools, overlapping with the monitoring contained under Article 7 of the FCNM, constitutes another theme that has attracted the ACFC's attention: the organisation and content of religious education classes and the attitudes of intolerance or hostility from fellow students and/or teachers are used as assessment factors to highlight the challenges of state-sponsored religious education, even when optional. ${ }^{48}$ Instances where "established" churches in a given state take advantage of their position to force collective prayer upon public schools, to display religious symbols for non-academic purposes, or to perform religious rituals on school grounds are stigmatized by the committee. ${ }^{49}$ In such instances, calls for secular instruction are made by the ACFC. ${ }^{50}$ The situation on the ground with respect to mandatory religious education (even when exemptions are provided) shows, at times, the limitation of the committee's approach in creating "space" for religious minority protection. In the example of Cyprus, for instance, parents of learners belonging to religious minorities still preferred 
their children to take part in the religious classes of the majoritarian religion in order to avoid leaving them without supervision for these didactic hours. ${ }^{51}$

The need for schools and education systems to provide adequate alternative activities for pupils that opt out from religious education is emphasized and, in parallel, religious dress in schools is also considered. The example of the niqab in British schools is treated as a subject matter of policy-making where broader consultation with religious communities was encouraged, particularly as the state was invoking arguments for its prohibition on the basis of security, safety, and learning concerns. ${ }^{52}$

Specific religious practices are occasionally also addressed. The example of circumcision in Sweden ${ }^{53}$, Finland ${ }^{54}$, and Denmark ${ }^{55}$ is one such case. The ACFC attempted, in its discussions, to strike a balance between the respect of a religious tradition (the Jewish/Muslim one) and an interference by the state in the interest of the health of the children concerned. By requiring the performance of the process of circumcision by a licenced doctor or a certified person only, the ACFC sided with a de facto limitation of Article 8 of the FCNM, guided nevertheless by the principle of proportionality (i.e., in support of medically appropriate processes that do not cause unnecessary pain).

The ban of the ritual slaughter of animals in accordance with kosher rules (Judaism) and halal rules (Islam) has also appeared in the list of recurring issues since the third cycle of reporting. ${ }^{56}$ Similarly, the accommodation of the religious needs of workers to take holidays during days which are not state non-working days, without having to compensate with additional working days, has been discussed. ${ }^{57}$ This particular practice has been reported to involve the production of a certificate from the representative of the faith community to which the employee requesting the leave belongs, confirming the person's membership of that community. ${ }^{58}$ The use of names leading to association with minority religious groups has also been commented upon during the monitoring process. In circumstances where the registration of names of new-born children were used to establish affiliation with a particular (dominant) faith, the ACFC has recommended more "neutral" means of registration through independent authorities. ${ }^{59}$

The ACFC also responds, in its monitoring, to identifiable gaps in state legal systems in order to fulfil the content of Article 8 of the FCNM. In the case of the $\mathrm{UK}^{60}{ }^{6}$ the committee stressed the need for national legislation covering both direct and indirect religious discrimination, using a reference on the same issue from the work of the European Commission Against Racism and Intolerance (ECRI). In the same vein, the ACFC also had noted the need for reform of the blasphemy law in the country, which at that time covered only Christians. ${ }^{61}$

Finally, the ACFCF has been involved in the review of the work of dedicated state bodies and organizations for the protection of the rights of religious minorities. The focus has been on the rationale and decision-making powers of such bodies, but also on the degree to which their work establishes a de facto hierarchy among religious minority organizations, which ultimately further entrenches the dominant position of the "established" faith, while creating inequalities in the exercise of the right to manifest one's religion as per Article 8 of the FCNM. ${ }^{62}$

In a number of instances, the ACFC has been confronted with reports, according to which religious minorities face harassment and violence when manifesting their religious beliefs. ${ }^{63}$ In some cases, intimidation originates from the state (through its police officers) in the form of raids, excessive controls, and the interruption of legal religious manifestation practices. ${ }^{64}$ In other cases, the wearing of religious symbols triggers violent reactions and racist insults (e.g., against women wearing the hijab). ${ }^{65}$ It has subsequently called for the pursuit of "a secular approach" 66 , although it is not clear what the approach would entail in terms of diversity management, nor is it necessarily conducive to higher levels of harmonious coexistence in fragmented societies. The link to Article 6 of the FCNM is hard to miss in the case of Article 8 of the FCNM, but can perhaps be interpreted as an attempt from the ACFC to emphasize the role of religious identity in promoting a democratic 
and plural approach to social inclusion, especially as it has become, in both established and transitioning democracies, an important element of self-determination for national minorities.

Overall, the ACfc's approach has emphasized as its key guiding principles equality before the law and equal protection of the $\operatorname{law}^{67}$ to guide states in the implementation of religious freedoms. Additionally, any measures need to be taken in consultation with the religious minority groups concerned. ${ }^{68}$ The committee is also favourable to the collection of data on the religious composition of the population of a state, an otherwise contested issue, as a means and an indicator to draw more effective and appropriate policies on religious freedom. ${ }^{69}$ Yet, Article 8 of the FCNM deserves a more systematic approach from the ACFC given the prominence of religious identity and the new forms of religious discrimination emerging as a result of technological advancements (e.g., use of the internet) in public space and the media, or as connected to major societal events (e.g., the COVID-19 pandemic) and the use of social services more broadly. ${ }^{70}$ The expansion of the remit of issues under Article 6 of the FCNM could perhaps serve as an example and an analogy.

\subsection{Article 6 of the FCNM}

Article 6 of the FCNM is a provision that has an enhanced programmatic character when compared to the rest of the FCNM provisions. In its first paragraph, it obliges states to take measures to promote respect and understanding among groups, while in its second paragraph, it requires states to protect members of groups threatened due to their religious identity. ${ }^{71}$ In the words of the $\mathrm{AC}$, " $(\ldots)$ the scope of Article 6 is wide and ( ... States parties to the Framework Convention undertake ( .. ) to promote respect and mutual understanding among all persons living on their territory, irrespective of their ethnic, cultural, linguistic or religious identity, or their citizenship." 72 Initially framed as a "catchall provision" (Gilbert 2005, p. 178), the provision has been gradually transformed by the Advisory Committee into a space for the debate surrounding the shift of the understanding of the concept of "Leitkultur", interpreted against any connotation of cultural assimilation politics while shifting towards a more inclusive approach. ${ }^{73}$

This broad interpretation of the article highlights a vision in diversity management, including when concerning religious diversity, that treats difference as an asset and a means for enrichment. This vision of diversity management has been triggered as of the third cycle of monitoring onwards, due to the increasing levels of diversity encountered in European societies resulting from migration flows and the economic crisis of the 2000s. Inherently connected to Article 12 of the FCNM that deals with minority education, but also Article 9 of the FCNM that concerns how the media can and does influence the image and perception of minorities (Angst 2018, p. 151), Article 6 serves the purpose throughout ACFC monitoring of the measuring stick of "the general climate of acceptance or exclusion" (Angst 2018, p. 152) in a given state.

The ACFC, in its analysis related to Article 6 of the FCNM covering interethnic and intercultural relations, often engages with religious identity. It does so, however, from the perspective of a negative reading of the exercise of freedom of religious belief. The negative reading in question focuses on obstacles to the exercise of religious freedom and the full realization of religious identity for minority groups and their members. It is largely centered on highlighting the incitement and exploitation of the negative feelings of the majorities against the minorities (Angst 2018, p. 158), for example, as it occurs through hate speech or anti-Semitism and Islamophobia.

The case of Switzerland is interesting to further illustrate the duty of "authorities, at all levels, to react promptly to any manifestation of intolerance and to condemn it publicly without delay."74 The popular initiative in 2009 to ban the construction of new minarets in the Federal Constitution is connected both to the exercise of religious freedom through manifestation, but also to hateful and intolerant speech by political parties and a segment of the society. ${ }^{75}$ This duty of states, according to the ACFC, extends to "protect persons who may be subject to threats or acts of discrimination," among others, also on grounds 
of their religious identity. ${ }^{76}$ It entails "deliberate efforts" to create the ground for mutual respect, understanding, and cooperation, where "persons belonging to national minorities are recognised as integral elements of society, who effectively enjoy equal access to rights and resources" through social interaction and inclusion across difference. ${ }^{77}$ Making a firm distinction between assimilation and integration, the AC has used the Polish case as an opportunity to reiterate its vision on religious diversity management: non-conformity with the "dominant", "mainstream", or prevailing view of national identity should be interpreted to suggest the possibility and even desirability of plural religious identities in European states, with due respect paid to the historical role of the dominant faiths in each context. The risk in a different case is identified as being "exclusionary" for religious communities $^{78}$ when accessing rights through arbitrary and unjustified distinctions. ${ }^{79}$

Related also to the second paragraph of Article 6 of the FCNM, a typical focus of the ACFC's monitoring analysis concerns instances of violence directed against religious minorities and the targeting of members of the groups in question, as well as their property and religious buildings. ${ }^{80}$ Expressions of hostility against Muslims, for instance, are noted in the opinion on the Russian Federation (third cycle), with emphasis placed on women wearing a hijab. ${ }^{81}$ Non-mainstream Muslim groups are also mentioned as targets of a perceived overlap between certain types of Muslim identity with terrorism, leading to the radicalization of public opinion. ${ }^{82}$ Likewise, concerns over the security situation of the Jewish community when manifesting their faith visibly through religious symbols is considered in the AC's opinion on Sweden (third cycle). A considerable amount of AC comments focus additionally on statements, whether by politicians, ${ }^{83}$ media outlets ${ }^{84}$, but also on the internet, that target religious minority groups. Private institutions are not excluded from the span of the committee's monitoring. A third component of state-related action that poses limits to the exercise of religious freedoms of minorities concerns the police and the judicial system of a given state. In this last context, issues of excessive force or in discriminatory patterns in decision-making are highlighted. ${ }^{85}$

Beyond this core of recurring issues under Article 6 of the FCNM, there is occasional diffusion in the reference to activities that thematically belong to the remit of other FCNM articles. For example, in its opinion on Bosnia and Herzegovina (third cycle), the AC referred to religious education in schools under Article 6, and not under Article $12 .{ }^{86}$ While the consideration of public education as a means to foster "ethnic belonging" is legitimate, the committee considers the questions of opt-outs and parental choice in the same context. ${ }^{87}$ Another example concerns the reference to ritual animal slaughter in the AC's opinion on Poland (third cycle) under Article 6 of the FCNM, but also under Article 5 of the FCNM, this time to highlight the nature and features of the public debate surrounding the issue. ${ }^{88}$ This kind of diffused referencing may not be conducive to the clear categorization of issues within a monitoring exercise such as the one undertaken by the FCNM, but at the same time signals the difficulty to draw consistent, dividing lines in the issues related to minority religious identity, especially as the private religious belief becomes public and vice-versa.

More rarely, the ACFC chooses to focus on the impact of measures undertaken by states in their attempts to instrumentalize the majority identity and social cohesion for assimilation purposes, as opposed to fostering the exercise of minority religious freedoms. In one of its rare references to the concept of harm caused to religious minority groups as a result of state behaviour, the AC states:

"Moreover, while Pomaks indicate that they generally have good relationships with the rest of the population on an individual level, many report being advised that if they wish to have successful careers, particularly in politics or the civil service they should refrain from mentioning their belonging to this group." 89

Three specific themes are repetitive under Article 6 of the FCNM: First, regarding places of worship and the manifestation of religion, the ACFC has identified in individual cases the difficulty for religious minorities to gain planning permission to build places of worship. ${ }^{90}$ By encouraging state authorities to support intercultural dialogue with 
religious minorities, the ACFC's approach follows a "soft governance" approach, with often mitigated results. In the example in relation to the building of a mosque in Denmark, the ACFC noted under Article 6 the need for Danish authorities to address the claim. ${ }^{91}$ Planning permission was given soon thereafter. ${ }^{92}$ It has been unclear how the $A C^{\prime}$ s recommendation influenced national authorities' decision-making. Similarly, the AC has supported religious minorities' claims for the allocation of burial sites, in a non-discriminatory manner, with respect to the burial customs of the minority religions concerned. ${ }^{93}$

Second, on the wearing of religious apparel, a characteristic opportunity for the AC to consider the issue concerned the wearing of the niqab (full face veil) in schools. ${ }^{94}$ In the context of the guidance on school uniforms issued by the government, the AC found:

"that the governing boards of schools in England already had the right to set their own regulations concerning school uniform and that most have opted for a permissive approach. There is risk that the new guidance may be interpreted by schools in a way that restricts the right of every person belonging to a national minority to manifest his or her religion and/or belief." ${ }^{\prime 95}$

The ACFC further stressed the need for consultation with minority religious communities on such decisions/policies. ${ }^{96}$ The committee's stance has been of an accommodative nature, encouraging the manifestation of religious difference towards a tolerant and pluralistic society, which is in line with Article 6(1) of the FCNM.

Third, in connection to islamophobia and discrimination against Muslims, the AC's reviewing and monitoring record has included the issue of multiple discriminatory practices against Muslims in its more recent work. It has additionally done so regardless of a possible migrant background that would tentatively exclude them from the scope of the application of the convention. In its opinion on Switzerland, the ACFC noted, for example, how Muslims were negatively stereotyped during the electoral campaign of 2007 , combined with another occasion on the launching of a popular initiative to ban the building of minarets. ${ }^{97}$ Similarly, in its opinion on the Netherlands, for the same cycle, the committee highlighted the frequency of expressions of hostility towards immigrants in the political and public debate as related to the growing anti-Muslim and anti-immigrant discourse used by some politicians. ${ }^{98}$

The range of state practices impacting members of Muslim minorities is overall broad: these include treatment by police enforcement officers; hate speech, availability of burial sites; food industry and processing regulations (e.g., halal meet processing); male circumcision; the building of places of workshop; or religious holidays and dress, to name a few. This group of issues targeting the particular minority groups is considered across a variety of convention articles by the ACFC without the addition of concrete criteria and evaluation parameters (Henrard 2019, p. 120).

\subsection{Article 5 of the FCNM}

Article 5(1) of the FCNM serves as a starting point to outline the conditions that need to be met for members of (religious) minorities to be able to effectively enjoy their culture and develop their identity. It imposes a duty on states parties to "promote the conditions necessary for persons belonging to national minorities to develop their culture, and to preserve the essential elements of their identity, namely their religion ( . . ) and cultural heritage." In that sense, the content of this particular provision contributes to the wider web of protection of religious freedoms as a guarantee against assimilation.

Article 5(2) explicitly states that "[w]ithout prejudice to measures taken in pursuance of their general integration policies, the Parties shall refrain from policies and practices aimed at assimilation of persons belonging to national minorities against their will and shall protect these persons from any action aimed at such assimilation." Religious affiliation, to the extent that it can be understood as cultural identity, in line with Article 5(2) of the FCNM, has been linked to societal integration based on a mutual adaptation between the majority and minorities, avoiding the imposition of a dominant culture. ${ }^{99}$ Often, cultural 
heritage and minority identity happen to be determined by religion as well, ${ }^{100}$ insofar as they "include an engagement with issues of general relevance within the community, such as $(\ldots)$ religious activities $(\ldots).)^{\prime 101}$

In the $\mathrm{AC}^{\prime}$ 's monitoring, this is reflected in recurring calls for states to enact legislation that provides "clear legislative guarantees"102, stressing, however, the limited impact of such legislation in societies where religious minorities are marginalised and excluded. ${ }^{103}$ State intervention must, therefore, aim to "enhance[e] the cultural confidence" of minority group members while contributing to their socio-economic integration in order for legislative frameworks to become more meaningful. As such, Article 5 of the FCNM operates as a multi-factor provision that combines legal, institutional, political, and social parameters, if it is to be successfully implemented (Roter 2018, p. 131). The protection of religious property and religious sites, the return of confiscated religious property to religious minorities, and the organization of religious education are typical focal issues that are relevant for religious minorities in the ACFC's cycles of monitoring. ${ }^{104}$ These themes are in consonance with Article 6 of the FCNMs' monitoring themes. More recently, the provision of financial support of states to minority groups has increasingly attracted the attention of the ACFC. The general approach of the committee has interpreted the duty of the states to provide financial support that not only reflects the different kinds of minorities, including numerically smaller ones, but also the diversity within minority groups themselves (e.g., on the basis of gender or age criteria), in order to address obstacles that prevent segments of these groups to access minority protection. Recognition of intra-minority diversity is particularly crucial for religious groups that more often than not have been treated as homogenous and static groups. This, combined with a more socio-economic assessment of the monitoring of the implementation of Article 5 of the FCNM holds the promise of a more dynamic understanding of religious identity in Europe.

As essential is the obligation of states contained in Article 5 of the FCNM to prevent forced assimilation of religious groups whose identity is non-mainstream and threatened by larger (dominant) cultures and religions (Roter 2018, p. 142). Combined with the need to follow "a balanced approach, based on a long-term view, endeavouring both to achieve the objectives of integration ( . . ) and to meet the need to protect the rights of persons belonging to minorities in terms of the preservation and development of their identity" ${ }^{\prime 105}$, Article 5 of the FCNM is unambiguously treated, in the later cycles of ACFC monitoring, as an instrument provision, contributing to guiding states against assimilation, including on the basis of religious identity. This effort is opposed to exclusivist nationbuilding policies (e.g., when recognizing public holidays. exclusively those associated with the dominant religion) as well as to considerations of religious identity as static cultural heritage, depriving groups from evolution, but also states from adjusting to contemporary societal challenges. But as societies change and as expressions of religious identity are moving online and are becoming digitalized, Article 5 of the FCNM will relate to the religious identity protection of minorities in new ways.

\section{Religious Minority Identity in the FCNM Frame: Some Concluding Remarks}

For religious freedom and religious diversity management purposes, the ACFC's approach has been conducive to an organic growth of both the standards developed and issues covered. In more technical terms, the use of indicators and benchmarks within FCNM monitoring has evolved to constitute a more viable approach towards the steadily slow yet progressive realization of their obligations by states under the convention (Brems 2009, pp. 354-55). The lack of justiciability of the convention for individual cases and the absence of remedies obviously affect the character of not only the provisions contained within the FCNM (which are largely programmatic and aspirational), but also their monitoring, insofar as the ACFC enjoys a certain discretion in highlighting legal and policy issues that it deems important for minorities. With religious minorities not traditionally included under the umbrella concept of "national minorities", the ACFC has managed, nevertheless, to begin framing religious minority rights standards and support 
measures as an aid to integration and against assimilation (Berry 2016, p. 18). It has also successfully identified systematic religious discrimination, including on the collective level, with the help of a liberal interpretation of the concept of "national minority."

The design of the FCNM-and especially Article 3(2)—suggest, however, that the convention awards individual rights, although most of them can be exercised "in community with others." In the era of religious hatred, anti-Semitism, and Islamophobia, it appears untenable to argue that the obligation of states is limited to the individual dimension of the exercise of religious rights. The essence of state obligations contained in Article 6 of the FCNM would contradict this approach: the obligation to promote intercultural dialogue and tolerance, including between religious groups, places a considerable burden on states to act on a number of levels that implicitly acknowledges that members of religious minorities certainly act as individuals, but also as groups members. Taking appropriate measures to reverse religious hatred, including among public officials, or collecting accurate and balanced reporting on religious hate crimes, by no means suggests that religious minorities are constituted by individuals. To the contrary, it is the collective dimension that requires the state's attention. In other words, the state is called to manage (biased) "perceptions" of religious difference that operate both on the level of the individual, but equally on that of the group. Claiming that only one dimension is relevant is contradictory and leads to a restrictive interpretation of the FCNM.

Relations between states and religious minorities (in particular Muslims) are otherwise mostly regulated through behavioural norms, such as kosher/halal meat regulation or prayer times/religious holidays arrangements (Bahçecik 2020, p. 598). A systematic classification of the $\mathrm{AC}^{\prime}$ s monitoring as it relates to religious freedoms can be evaluated more broadly, either in terms of limitations on state behaviour and the exercise of religious freedoms (negative rights), or in terms of the duties/obligations of the state vis-à-vis religious minorities (positive rights). This dualist categorisation can be justified by the fact that the ACFC considers states as its prime interlocutors in the frame of the monitoring process. Within that limitation, the committee does not always factor in the realities of the multiple identification of individuals, but also the complex processes of community formation through (constantly evolving) shared practices. ${ }^{106}$ Still, whether one refers to the marketing of halal/kosher food, the practice of circumcision, or the construction of mosques, churches, and religious burial practices, the $\mathrm{AC}^{\prime}$ 's monitoring has managed to extend its remit beyond legislative and judicial frameworks and decision-making processes. This extension is significant, though not self-sufficient, as religion as an identity marker is gaining significance and complexity in multicultural European societies and political spaces.

Religious minority identity is presently an amalgam of faith, culture, and heritage, offering a differing imagery of one's personhood and/or group affiliation (Beaman 2019), when compared to that of the majority. In the monitoring work of the ACFC, religious minority identity has been shown to become an instrument of exclusion, of discrimination, and of de-humanization through hate speech and hate crime. Through a combination of references to Articles 6, 7, and 8 of the FCNM, the ACFC attempts to contribute to the "art of living with difference" as an "everyday problem" (Bauman 2011, p. 370). Despite the committee's sustained efforts over four completed cycles of monitoring, and with a fifth one under way, it is worth wondering to what extent the FCNM as a legal text has prevented the erosion of trust in the promise and premise of minority rights standards in Europe. Admittedly, states may not be always receptive to an open conversation about majoritarian culture, especially in times where religion is becoming the "new race." It is this gap that the ACFC can meaningfully fill as a norm mediator for religious minorities.

Funding: This research received no external funding.

Conflicts of Interest: The author declares no conflict of interests. 


\section{Notes}

1 The ACFC, as per CM Resolution (97) 10, complements the task of the Committee of Ministers by examining state reports made public and by preparing an opinion on measures taken by individual states to meet the obligations of the FCNM. The ACFC may seek information from a variety of sources, including states themselves, non-governmental organizations, and civil society, as well as experts.

2 The ACFC has additionally drafted thematic commentaries on specific topics as follows to assist in the interpretation of the convention: on education (Thematic Commentary No. 1, 2006), on participation (Thematic Commentary No. 2, 2008), on language rights (Thematic Commentary No. 3, 2012), and on the scope of application of the FCNM (Thematic Commentary No. 4, 2016) (available online: https:/ / www.coe.int/en/web/minorities/thematic-commentaries).

3 ACFC Thematic Commentary No. 4 on the Framework Convention-“'A Key Tool to Manage Diversity through Minority Rights: The Scope of Application of the FCNM", adopted on 27 May 2016, ACFC/56DOC(2016)001.

4 ACFC Thematic Commentary No. 4 (2016). For more on this point, see also the following section of this article.

5 This tension is not unique to religion as a marker of minority identity. It extends to other aspects of minority culture, such as language. For a general view on this point, see indicatively, Henrard (2019).

6 ACFC Thematic Commentary No. 4 (2016), at para. 5, p. 5.

7 ACFC Thematic Commentary No. 4 (2016), at para. 2, p. 4.

8 See, for example, the 2012 State Report submitted by Switzerland where it was noted that: "The aim of integration policy is to enable migrants to participate in economic, social and cultural life in the same way as the Swiss ( ... ). Efforts to promote integration which are aimed at giving migrants a stronger sense of responsibility and supporting them ( ...) go hand in hand with an anti-discrimination policy." (Third Report submitted by Switzerland pursuant to Article 25, paragraph 2 of the FCNM, ACFC/SR/III(2012)001, 26 January 2012, at p. 15).

9 See, for example, the case of Germany from its fourth cycle opinion (at para. 18).

10 See AC/FCNM compilation of opinions of the AC relating to Article 3 of the FCNM (second cycle), February 2016, pp. 75-76.

11 ACFC Thematic Commentary No. 4 (2016).

See the cases of Uner $v$ Netherlands (2005) judgment of 05.07.2005, Appl. N. 46410/99, Boultif v Switzerland (2000), judgment of 5 October 2000, Appl. N. 54273/00 and Slivenko v Latvia, Appl. N. 48321/99, judgment of 9 October 2003. In Biao v Denmark (2016) judgment of 24 May 2016, Appl. N. 38590/10 that qualifies this duty to some extent.

See for instance the 2015 CERD Report on the Netherlands which noted the same transfer of onus for integration on migrants (CERD/C/NLD/CO 19-21 od 28 August 2015, at para. 21(a). ACFC Thematic Commentary No. 4 (2016), at p. 21 et seq. By contrast, Articles 10(2), 11(3), and 14(2) of the FCNM can be limited to 'old' minorities (Hofmann et al. 2018, p. 16).

AC/FCNM Thematic Commentary No. 4, at para. 79. Today's population mobility is essentially an important factor towards a more flexible approach.

At the time of writing, several attacks in the name of Islam, but in reality more according to Islamist motivations, were carried out in Europe, such as the beheading of Samuel Paty in a Parisian suburb, the attack outside Notre Dame in Nice with further victims, as well as the attack outside a synagogue in Vienna with several left dead and wounded. See indicatively, Nossiter and Katrin (2020).

ACFC Thematic Commentary No. 4 (2016) at p. 26.

ACFC Thematic Commentary No. 4 (2016), at para. 68, p. 26.

ACFC Thematic Commentary No. 4 (2016), at para. 85, p. 33.

These can be formal recognition, citizenship, length of residency, territorial criteria for application, numerical criteria, support by 'kin states', or specific identity markers, including religion (Cf. ACFC Thematic Commentary No. 4 (2016), at p. 12 et seq.) For a recent example, combining several of the above criteria, see 5th State Report Submitted by Germany, 31 January 2019, $\mathrm{ACFC} / \mathrm{SR} / \mathrm{V}(2019) 001$ at p. 132. para. 62); Second Opinion on Bulgaria, FCNM/II(2012)001 (at para. 131); Third Opinion on Bulgaria, ACFC/OP/III(2014)001 (at para. 81).

Opinion on the Russian Federation (first cycle), ACFC/INF/OP/I(2003)005 criticizing the 2001 Law on Political Parties that prohibited the establishment of political parties also on the basis of religious belonging (Article 9(3) of the Law (at para. 69); Second Opinion on the Russian Federation, ACFC/OP/II(2006)004 (at para. 162). Third Opinion on Bulgaria, ACFC/OP/III(2014)001 (at paras. 80-82). Second Opinion on Norway, ACFC/OP/II(2006)006 (at para. 93).

The repeated use of the term 'religious instruction' in the opinion is interesting insofar as the notion of instruction is less used scientifically due to its potential link with 'indoctrination'. 
European Court of Human Rights, Folgero v. Norway, Appl. N. 15472/02, 29 June 2007.

Second Opinion on the Russian Federation, ACFC/OP/II(2006)004 (at para. 165).

Second Opinion on the FYROM, ACFC/OP/II(2007)002 (at para. 100).

Third Opinion on the Russian Federation, ACFC/OP/III(2010)010 (at para. 132).

Third Opinion on the Russian Federation, ACFC/OP/III(2010)010, on Chechens (at para. 142).

Article 8 of the FCNM stipulates: "The Parties undertake to recognise that every person belonging to a national minority has the right to manifest his or her religion or belief and to establish religious organisations and associations."

Opinion on Bulgaria (first cycle), ACFC/OP/I(2006)001, at para. 65; Opinion on Denmark (first cycle), ACFC/INF/OP/I(2001)5, at para. 29; Opinion on Finland (first cycle) ACFC/INF/OP/I(2001)2, at para. 29; Opinion on Georgia (first cycle), ACFC/OP/I(2009) 001, at para. 90; Opinion on Norway (first cycle), ACFC/OP/I(2003)003, at para. 39. See also Second Opinion on Denmark, ACFC/INF/OP/II(2004)005, at paras. 109-10.

See the example of the Opinion on Georgia (first cycle), ACFC/OP/I(2009)001 noting how the Georgian Orthodox Church was both protected as a church and as a public entity, while other religious groups could only register as non-governmental/nonprofit-making private-law associations (at para. 92).

See the discussion in the Second Opinion on Finland, ACFC/OP/II(2006)003, on the allocation of a share of corporate tax to the Evangelical Lutheran Church and the Orthodox Church, among other privileges (at para. 91).

Opinion on Albania (first cycle), ACFC/INF/OP/I(2003)004 concerning the Greek and Aromanian/Vlach minorities (at para. 43); Opinion on Georgia (first cycle), ACFC/OP/I(2009)001 with reference to the Armenian minority (at para. 93). See also the Second Opinion on Croatia, ACFC/INF/OP/II(2004)002 concerning property restitution of the Jewish community (at para.102). Opinion on Kosovo (second cycle), ACFC/OP/II(2009)004 (at para. 148); Opinion on Montenegro (second cycle), ACFC/OP/II(2013)002 (at para. 110); Opinion on the Russian Federation (second cycle), ACFC/OP/II(2006)004 (at para. 174); Opinion on Croatia (third cycle), ACFC/OP/III(2010)005 (at para. 121).

Opinion on Bosnia and Herzegovina (first cycle), ACFC/INF/OP/I(2005)003 (at para. 75); Opinion on Georgia (first cycle), ACFC/OP/I(2009)001 (at para. 93).

Opinion on Moldova (first cycle), ACFC/INF/OP/I(2003)002 (at para. 50); Opinion on Montenegro (first cycle), ACFC/OP/I(2008)001 (at para. 66).

Opinion on Poland (third cycle), ACFC/OP/III(2013)004, at paras. 61-62. In this case, a noticeable difference in the speed of the procedure was noted between properties belonging to the Roman-Catholic Church as opposed to those claims issued by the Orthodox Church, the Lutheran Church, and the Union of Jewish Religious Communities.

Opinion on Azerbaijan (first cycle), ACFC/INF/OP/I(2004)001 at paras. 46-47; Opinion on Estonia (first cycle), ACFC/INF/OP/I (2002)5, at para. 34; Opinion on the Russian Federation (first cycle), ACFC/INF/OP/I(2003)005 at para. 72; Opinion on the Russian Federation (second cycle), ACFC/OP/II(2006)004 at para. 172; Opinion on North Macedonia (fourth cycle), ACFC/OP/IV(2016)001 at para. 53.

Opinion on Serbia (second cycle), ACFC/OP/II(2009)001 at para. 142.

Opinion on Azerbaijan (third cycle), ACFC/OP/III(2012)005 at para. 72. Muslim minority religious communities in this particular instance were noted to be required to go through a double registration purpose, with consequences for the communication between the different branches of the same faith.

Opinion on Moldova (second cycle), ACFC/INF/OP/II(2004)004 at para. 79.

Opinion on Moldova (second cycle), ACFC/INF/OP/II(2004)004 at paras. 79-80.

Opinion on North Macedonia (second cycle), ACFC/OP/II(2007)002 at para. 103; Opinion on Serbia (second cycle), ACFC/OP/II (2009)001 at para. 143.

Opinion on Serbia (second cycle), ACFC/OP/II(2009)001 at para. 39; Opinion on Serbia (third cycle), ACFC/OP/III(2013)006 at paras. $41-43$.

Opinion on Bulgaria (second cycle), FCNM/II(2012)001 at paras. 134-36, concerning the Muslim minority claims of state interference with their internal organisation; Opinion on Moldova (second cycle), ACFC/INF/OP/II(2004)004 at para. 78.

Opinion on Georgia (first cycle), ACFC/OP/I(2009) at paras. 98-99; Opinion on Norway (first cycle), ACFC/OP/I(2003)003 at paras. 39-40.

Opinion on Georgia (second cycle), ACFC/OP/II(2015)001 at para. 62; Opinion on Serbia (second cycle), ACFC/OP/II(2009)001 at para. 145.

Opinion on Cyprus (third cycle), ACFC/OP/III(2010)002 at para. 117 in relation to the Maronite community.

Opinion on Cyprus (fourth cycle), ACFC/OP/IV(2015)001 at para. 42.

Opinion on the UK (second cycle), ACFC/OP/II(2007)003 at para. 158.

Opinion on Sweden (first cycle), ACFC/INF/OP/I(2003)006 at para. 40.

Opinion on Finland (second cycle), ACFC/OP/II(2006) at para. 93. 
Opinion on Denmark (fourth cycle), ACFC/OP/IV(2014)001 at para. 69.

Opinion on Poland (third cycle), ACFC/OP/III(2013)004 at para. 91; Opinion on Denmark (fourth cycle), ACFC/OP/IV(2014)001 at para. 68.

Opinion on Poland (second cycle), ACFC/OP/II(2009)002, at para. 109.

Opinion on Poland (third cycle), ACFC/OP/III(2013)004, at para. 89.

Opinion on Denmark (third cycle), ACFC/OP/III(2011)002 at para. 75.

Opinion on the UK (first cycle), ACFC/INF/OP/I(2002)6 at paras. 59-60.

Opinion on the UK (first cycle), ACFC/INF/OP/I(2002)6 at para. 60. The Act was subsequently entirely abolished.

Opinion on Georgia (second cycle), ACFC/OP/II(2015)001 at para. 62.

See, for example, the opinion on Kosovo (third cycle), ACFC/OP/III(2013)002 at para. 91

Opinion on Moldova (third cycle), ACFC/OP/III(2009)003 at para.106, with reference to Muslim believers in the country and an accompanying reference to ECtHR case-law, in particular the case of Masaev v.Moldova.

Opinion on the Russian Federation (third cycle), ACFC/OP/III(2010)010 at para. 151.

Opinion on Kosovo (third cycle), ACFC/OP/III(2013)002 at para. 90.

Opinion on Croatia (first cycle), ACFC/INF/OP/I(2002)003 at para. 39.

Opinion on Montenegro (first cycle), ACFC/OP/I(2008)001 at para. 66.

Opinion on Albania (third cycle), ACFC/OP/III(2011)009 at para. 116.

For a similar point, see Malloy (2018) at 188.

Article 6 of the FCNM reads: "1. The Parties shall encourage a spirit of tolerance and intercultural dialogue and take effective measures to promote mutual respect and understanding and co-operation among all persons living in their territory, irrespective of those persons' ethnic, cultural, linguistic or religious identity, in particular in the fields of education, culture and the media. 2. The Parties undertake to take appropriate measures to protect persons who may be subject to threats or acts of discrimination, hostility or violence as a result of their ethnic, cultural, linguistic or religious identity."

The resistance of some states such as Austria, Denmark, and Germany is noted with respect to the widened scope of application of Article 6 of the FCNM. For more on this point, see Angst (2018) at 153.

Opinion on Germany (third cycle), ACFC/OP/III(2010)003 at para. 87.

Opinion on Switzerland (third cycle), ACFC/OP/III(2013)001, at para. 65.

Opinion on Switzerland (third cycle), ACFC/OP/III(2013)001, at para. 63.

Opinion on Poland (fourth cycle), ACFC/OP/IV(2019)003, at para. 74.

Opinion on Poland (fourth cycle), ACFC/OP/IV(2019)003, at para. 79. The use of statistics in the opinion (at para. 81 et seq.) is worth noting.

Opinion on Poland (fourth cycle), ACFC/OP/IV(2019)003 at para. 102 (under Article 9 of the FCNM).

Opinion on Switzerland (fourth cycle), ACFC/OP/IV(2018)003, at para. 26 (under Article 3 of the FCNM).

For instance, references to vandalism against the Holocaust memorial are included in the Opinion on Armenia (third cycle), ACFC/OP/III(2010)006, at para.71; in the Opinion on Bosnia Herzegovina (third cycle), ACFC/OP/III(2013)003 in relation to Serbian Orthodox churches, Catholic churches, and mosques, at para. 99; in the Opinion on Bulgaria (third cycle), ACFC/OP/III(2014)001 for attacks on mosques, at para. 74; in the Opinion on Romania (third cycle), ACFC/OP/III(2012)001 for attacks on Jewish cemeteries in Bucharest, at para.106; Opinion on Bosnia Herzegovina (fourth cycle), ACFC/OP/IV(2017)007, at para. 75.

Opinion on the Russian Federation (third cycle), ACFC/OP/III(2011)010, at para. 91.

Opinion on the Russian Federation (third cycle), ACFC/OP/III(2011)010, at paras. 91-92.

See, for example, the Opinion on Bulgaria (third cycle), ACFC/OP/III(2014)001 on the scapegoating of Pomaks by politicians together with the Turks for the country's socio-economic conditions (at para. 66).

Opinion on Kosovo (third cycle), ACFC/OP/III(2013)002 criticizing the reporting of Radio Television Kosovo on manifestations surrounding the monastery in Decan/Decani municipality and vandalism against Orthodox cemeteries (at para. 71); Opinion on Romania (third cycle), ACFC/OP/III(2012)001 on anti-Semitism in the public media and internet (at para. 106); Opinion on the UK (third cycle), ACFC/OP/III(2011)006, at para. 101.

See, for example, the Opinion on Austria (third cycle), ACFC/OP/III(2011)005, at para. 60; Opinion on Moldova (third cycle), ACFC/OP/III(2009)003 on frequent police raids on Muslim believers (at para. 91).

Opinion on Bosnia and Herzegovina (third cycle), ACFC/OP/III(2013)003, at para. 92.

A similar example again on education can be found in the Opinion on Spain (third cycle), ACFC/OP/III(2012)03 on the teaching of Islam in public schools (at para. 76), discussed again under Article 6 of the FCNM. 
The ACFC's comments stressed the intolerant attacks on Muslims for defending the practice, revealing anti-Semitic and antiMuslim public opinion sentiments.

Opinion on Bulgaria, ACFC/OP/III(2014)001, at para. 66.

90 See, for example, the opinions of Bosnia and Herzegovina, ACFC/INF/OP/I(2005)003, at para.75; Second opinion on Russia, ACFC/OP/II(2006)004 at para. 173; Opinion on Slovenia, ACFC/INF/OP/I(2005)002 at para.46; Second opinion on Slovenia, ACFC/OP/II(2005)005, at para.98; Second opinion on Spain, ACFC/OP/II(2007)001, at para. 110. Second opinion on Denmark, adopted on 9 December 2004, ACFC/INF/OP/II(2004)005 at para. 88.

It is unclear how the ACFC's recommendation influenced national authorities' decision-making.

Second opinion on Moldova, ACFC/INF/OP/II(2004)004 at para. 84; Second opinion on Finland, ACFC/OP/II(2006)003, at para. 90; Opinion on Montenegro, ACFC/OP/I(2008)001, at para. 66. Second opinion on the UK, ACFC/OP/II(2007)003, at paras. 158, 161.

Ibid, at para. 158. See also UK Department for Education-School Uniform: Guidance for governing bodies, school leaders, school staff and local authorities, September 2013, in particular p. 6.

Ibid, at para. 161.

Second Opinion on Switzerland, ACFC/OP/II(2008)002 at para. 88.

Second Opinion on the Netherlands, ACFC/OP/II(2013)003, at para. 57.

ACFC Thematic Commentary No. 4 (2016) at para. 44.

Opinion on Switzerland, ACFC/INF/OP/I (2003)007 at para. 29.

Opinion on the Russian Federation, ACFC/OP/III(2011)010 at para. 74.

Opinion on Georgia, ACFC/OP/I(2009)001, at para. 179.

Opinion on Bosnia Herzegovina, ACFC/INF/OP/I(2005)003, at para. 55.

See indicatively, the second cycle Opinions on Georgia, ACFC/OP/II(2015)001 (at paras. 38 et seq.), on Kosovo ACFC/OP/I(2009)004 (at paras. 104 et seq.), and on Ukraine ACFC/OP//II(2008)004 (at paras. 88 et seq.); also, the third cycle Opinions on Armenia, ACFC/OP/III(2010)006 (at paras. 62 et seq.), on Azerbaijan ACFC/OP/III(2012)005 (at paras. 42 et seq.), and on Ukraine, ACFC/OP/III(2012)002 (at paras. 57 et seq.), or the fourth cycle Opinions on Cyprus, ACFC/OP/IV(2015)001 (at paras. 26 et seq.) and Moldova, ACFC/OP/IV(2016)004 (at paras. 32 et seq.).

Opinion on Georgia (first cycle), ACFC/OP/I(2009)001, at para. 60.

106 This does not mean, however, that the ACFC is not aware of these dimensions. See, for example, ACFC Thematic Commentary No. 4 (2016) at p. 3 for examples.

\section{References}

Angst, Doris. 2018. Commentary of Article 6 of the Framework Convention for the Protection of National Minorities. In The Framework Convention for the Protection of National Minorities-A Commentary. Edited by Rainer Hofmann, Tove H. Malloy and Detlev Rein. Leiden: Brill, pp. 148-66.

Bahçecik, Şerif Onur. 2020. State, Religion and Muslims: Between Discrimination and Protection at the Legislative, Executive and Judicial Levels: An Overview. In State, Religion and Muslims. Edited by Melek Saral and Şerif Onur Bahçecik. Leiden: Brill, pp. 598-610.

Bauman, Zygmunt. 2011. Culture in a Liquid Modern World. Cambridge: Polity.

Beaman, Lori. 2019. The Protection of Religion as 'Culture' and 'History': Three Case Studies. In The Changing Terrain of Religious Freedom Sharkey. Edited by Jeffrey Green and Heather Sharkey. Philadelphia: University of Pennsylvania Press.

Berry, Stephanie E. 2016. The Siren's Call? Exploring the Implications of an Additional Protocol to the European Convention on Human Rights on National Minorities. International Journal on Minority and Group Rights 23: 1-38. [CrossRef]

Brems, Eva. 2009. Human Rights: Minimum and Maximum Perspectives. Human Rights Law Review 9: 354-55. [CrossRef]

Fontaine, Anna. 2018. Commentary of Article 7 of the Framework Convention for the Protection of National Minorities. In The Framework Convention for the Protection of National Minorities-A Commentary. Edited by Rainer Hofmann, Tove H. Malloy and Detlev Rein. Leiden: Brill, pp. 167-75.

Ghanea, Nazila. 2012. Are Religious Minorities Really Minorities? Oxford Journal of Law and Religion 1: 57-79. [CrossRef]

Gilbert, Geoff. 2005. Article 6. In The Rights of Minorities. Edited by Marc Weller. Oxford: Oxford University Press, pp. 177-91.

Henrard, Kristin. 2019. The half-hearted protection of new religious minorities' fundamental rights in Europe: A glass half empty and a glass half full. In Extending Protection to Migrant Populations in Europe. Edited by Caitlin Boulter, Tove H. Malloy and Roberta Medda-Windischer. London: Routledge, pp. 104-32.

Hofmann, Rainer. 2004. The work of the AC under the FCNM, with particular emphasis on the case of Germany. In Rethinking Non-Discrimination and Minority Rights. Edited by Martin Scheinin and Reetta Toivanen. Turku: Institute for Human Rights Åbo Akademi University, Berlin: Deutsches Institut fuer Menschenrechte, pp. 51-96. 
Hofmann, Rainer, Tove H. Malloy, and Detlev Rein, eds. 2018. Introduction. In The Framework Convention for the Protection of National Minorities-A Commentary. Leiden: Brill, pp. 3-21.

Malloy, Tove H. 2018. Commentary of Article 8 of the Framework Convention for the Protection of National Minorities. In The Framework Convention for the Protection of National Minorities-A Commentary. Edited by Rainer Hofmann, Tove H. Malloy and Detlev Rein. Leiden: Brill, pp. 176-88.

Nossiter, Adam, and Bennhold Katrin. 2020. The Politics of Terrorism in a Combustible Europe. The New York Times, November 9. Available online: https:/ / www.nytimes.com/2020/11/09/world/europe/france-austria-terrorist-attacks-marcon-kurz.html (accessed on 2 December 2020).

Phillips, Alan. 2002. The FCNM: A Policy Analysis. Minority Rights Group International, Policy Paper. London: MRG.

Roter, Petra. 2018. Commentary of Article 5 of the Framework Convention for the Protection of National Minorities. In The Framework Convention for the Protection of National Minorities-A Commentary. Edited by Rainer Hofmann, Tove H. Malloy and Detlev Rein. Leiden: Brill, pp. 126-47. 